\title{
Microstructure of coupled Al/gray cast iron obtained by molding and its effect on mass loss
}

\author{
*Mohamed Bouitna', Naïma Boutarek-Zaourar', Samir Mansour', Samir Mourad Chentouf ${ }^{2}$, Eric Mossang ${ }^{3}$ \\ 1. Laboratory of Materials Technology, Faculty of Mechanical Engineering and Process Engineering, University of Science and Technology \\ Houari Boumediene, B.P. 32 El Alia, 16111 Algiers, Algeria \\ 2. Department of Mechanical Engineering, School of Technology Superior, 1100 Notre-Dame Street West, Montreal, Quebec H3C 1K3, Canada \\ 3. NEEl Institute, National Center for Scientific Research, 25, rue des Martyrs, BO 166, 38042, Grenoble Cedex, France
}

\begin{abstract}
This study aims to consolidate the surface of gray cast iron with aluminum deposition by developing a method that combines the preparation and surface treatment in a single operation. The effect of the wall thickness of the castings on the microstructure of the formed layers was studied, and two thicknesses, $8 \mathrm{~mm}$ and $25 \mathrm{~mm}$, were studied. The formation of a continuous and homogeneous rich aluminum layer on the surface of the cast iron was observed. The formed layer is composed of two successive zones identified as two proeutectoid phases $\mathrm{FeAl}+\mathrm{FeAl} / \mathrm{FeAl}_{2}$ and single-phase $\mathrm{FeAl}$, which significantly increases the surface hardness. Furthermore, this change in surface composition makes it possible to reduce the mass of the immersed samples in a $1 \mathrm{M}$ hydrochloric acid solution during different exposure times (1 to 4 days). Consequently, a clear improvement in the corrosion resistance of the treated layers is highlighted.
\end{abstract}

Key words: gray cast iron; aluminum; coating; treatment in the mold; mass loss
CLC numbers: TG143.2
Document code: $\mathrm{A}$
Article ID: 1672-6421(201805-378-06

\begin{abstract}
Cast ast irons are used in industry due to their interesting mechanical properties and low manufacturing costs. Nevertheless, the performances of such alloys remain limited regarding some particular conditions of service (fatigue, abrasion, or corrosion). In fact, cracking occurs easily in graphite which causes mechanical failures, thereby reducing the mechanical resistance of the cast iron. Cast irons are widely used in applications involving resistance to abrasive wear. These parts can work under a wide variety of wear conditions, and the material structure can be modified to reinforce the friction properties. This structural modification can be obtained by localized quenching, or by superficial treatments ${ }^{[1]}$. Several studies have been conducted to investigate the effect of the alloying elements on the mechanical properties of gray cast irons ${ }^{[1-5]}$. It was found that aluminum could reduce quenching, refine the grains, give the graphite an inter-dendritic appearance,
\end{abstract}

\footnotetext{
*Mohamed Bouitna

Male, born in 1975, Ph.D candidate, Assistant Master at National Higher School of Technology since 2010 . He is currently working on the development of a new surface treatment technique on gray cast iron parts, using metal deposit by molding process. He is interested in the impact that the elements of the deposit can have on the microstructure, and the change of the mechanical and chemical properties of gray cast irons.

E-mail: mbouitna@yahoo.fr
}

Received: 2018-04-03; Accepted: 2018-07-02 and improve the corrosion resistance of cast irons. In addition, aluminum is used as a surface protector in metals against high temperature oxidation ${ }^{[6]}$ in gas turbines.

Bouitna $\mathrm{M}$ et al. ${ }^{[7]}$ reported an experimental study in order to consolidate the gray cast iron surface by introducing a paste of ferromanganese into the mold. The effect of the particle size of the paste on a continuous and homogeneous formed layer has been studied, and an improvement in the wear resistance of the treated cast iron induced by the surface transformation has been identified.

The objective of this study is to develop and characterize gray cast iron coated with an aluminum deposit, developing a method combining in a single operation the preparation and surface treatment in the mold, which can greatly improve the corrosion resistance of the treated layers.

\section{Experimental procedure}

Table 1 shows the chemical composition of the raw materials of the prepared cast iron alloy. The raw materials were melted inside an ordinary coke cupola.

The mold cavity was coated with a $0.7 \mathrm{~mm}$ thickness of aluminum layer. This treatment includes the preparation of the pasty substance, followed by 
Table 1: Chemical composition of raw materials used

$\begin{array}{lcccccc}\text { Raw material(wt.\%) } & \text { Fe } & \text { C } & \text { Si } & \text { Mn } & \text { P } & \text { S } \\ \text { New cast iron } & 93.8 & 3.6 & 1.35 & 0.95 & 0.225 & 0.067 \\ \text { Steel fall } & 99.43 & 0.12 & 0.10 & 0.30 & 0.05 & 0.001 \\ \text { Fe-Si } & 55.00 & - & 45.00 & - & - & -\end{array}$

treatment using this substance in the inner portion of the mold. These two steps can be explained as follows:

- Preparation of the pasty substance: aluminum powder $(0.5 \mathrm{~mm}$ in grain size) was obtained by a ball mill, and was dissolved in $30 \%$ ethanol to form a pasty substance.

- Processing in the mold: the inner walls of the mold were coated with the paste by a brush, followed by drying of the spread layer.
To highlight the effect of casting's wall thickness on the microstructure of the formed layer, two cast irons of 8 and $25 \mathrm{~mm}$ thick were prepared under the above-mentioned conditions. A sample in the form of a staircase with two steps of 8 and $25 \mathrm{~mm}$ and $50 \mathrm{~mm}$ in width (Fig. 1) was made. This sample allowed obtaining the two pieces (identified as E8 and E25) in the same molding operation, and consequently ensuring the same experimental conditions.
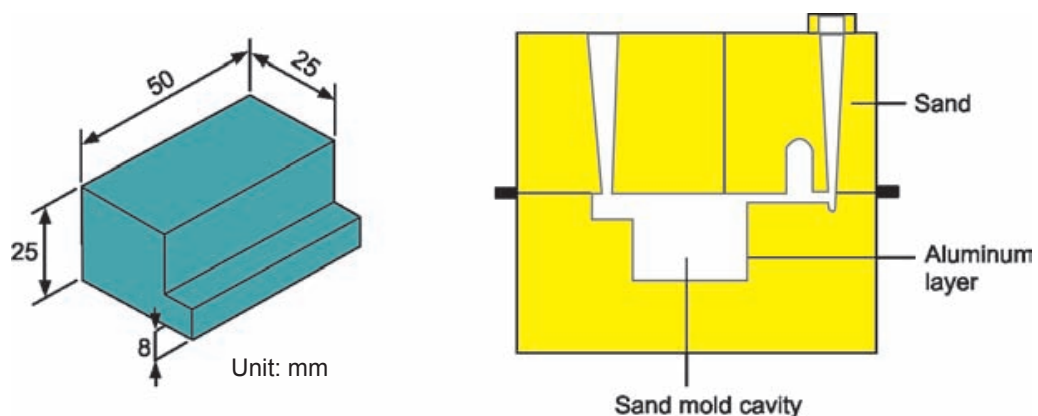

Fig. 1: Schematic of designed sample (a) to obtain two pieces with different thicknesses in a single operation and mold (b)

An atomic emission spectrometer Jobin Yvon-type 132F was used to identify the chemical composition of the pieces except carbon (light element cannot be detected by this method). The carbon element was confirmed by the $\mathrm{CO}$ and $\mathrm{CO}_{2}$ concentrations using a CS200 analyzer after combustion of the alloy. The metallographic observations were carried out, after nital etching $(4 \%){ }^{[8]}$ for $15 \mathrm{~s}$, using an optical microscope (EPIPHOT) and a scanning electron microscope (SEM, JEOL JSM 35X) coupled with an energy dispersive spectrometer (EDS). Grazing incidence X-ray diffraction (XRD) technique was used to identify the crystalline phases present at the surface. The experiments were performed using a Philips X'Pert PRO diffractometer with $\mathrm{Cu}-\mathrm{K} \alpha$ radiation $(\mathrm{A}=1.54056 \AA)$. A $0.02^{\circ}$ step $(2 \theta)$ and a 4 -second time per step were selected for the collection of all the spectra.

Vickers microhardness profiles were measured using a Wilson hardness tester. A load of $0.1 \mathrm{kgf}$ was applied without shocks or vibrations and maintained at its final value for $20 \mathrm{~s}$. The displacement of the indenter was conducted from the periphery to the workpiece core with a $75 \mu \mathrm{m}$ pitch in the cast iron and a step of 5 to $15 \mu \mathrm{m}$ in the formed layers.

Weight study of the part was based on the mass loss determination as a function of immersion time in $1 \mathrm{M}$ hydrochloric acid with a $1.035 \mathrm{~g} \cdot \mathrm{cm}^{-3}$ density. Four exposure durations ranging from 1 to 4 days were selected for the surface study. The other sample surfaces were coated with an adhesive to prevent any possible reaction with the immersion solution. The surface dimensions of the treated and control (untreated cast iron) samples are summarized in Table 2.

Table 2: Area of samples immersed in $\mathrm{HCl}$ solution (1 M)

$\begin{array}{rccc}\text { Samples } & \text { Control sample } & \text { E08 } & \text { E25 } \\ \text { Area }\left(\mathrm{cm}^{2}\right) & 5.53 & 0.725 & 3.00\end{array}$

In order to determine the mass loss, the samples were weighed before and after the immersion tests using an analytical balance with an accuracy of $\pm 0.01 \mathrm{~g}$. These samples were removed after $24 \mathrm{~h}$ of immersion, and then rinsed with distilled water and dried. This methodology allowed access to the mass loss variation as a function of the corroded thickness. Therefore, the mass loss $(\triangle P)$ can be related to thickness loss and corrosion rate $\left(\mathrm{mm} \cdot \mathrm{year}^{-1}\right)$ according to the following equation:

$$
\text { Corrosion rate }=3.65 \Delta P /(S \rho \Delta t)
$$

where $\Delta P$ is the mass loss (mg), $S$ is the area of the exposed surface $\left(\mathrm{cm}^{2}\right), \rho$ is the density of the metal $\left(\mathrm{g} \cdot \mathrm{cm}^{-3}\right)$, and $\Delta t$ is the exposure time (day).

\section{Results and discussion}

\subsection{Characterization of base material}

The chemical composition of the gray cast iron obtained after 
casting is summarized in Table 3, which is consistent with the literature ${ }^{[9-12]}$.

Table 3: Final chemical composition of gray cast iron (\%)

\begin{tabular}{cccccc} 
Fe & C & Si & Mn & P & S \\
\hline 93.87 & 3.15 & 1.90 & 0.64 & 0.31 & 0.12 \\
\hline
\end{tabular}

The gray cast iron surface morphology observed by SEM is shown in Fig. 2, which is consistent with the literature ${ }^{[9,13-17]}$.

Figure 2 shows that three phases can be observed in the gray cast iron microstructure: lamellar graphite (black arrow), pearlitic structure (red arrow), and phosphorous eutectic (yellow arrow). Phosphorus eutectic phase is present in all industrial irons in the

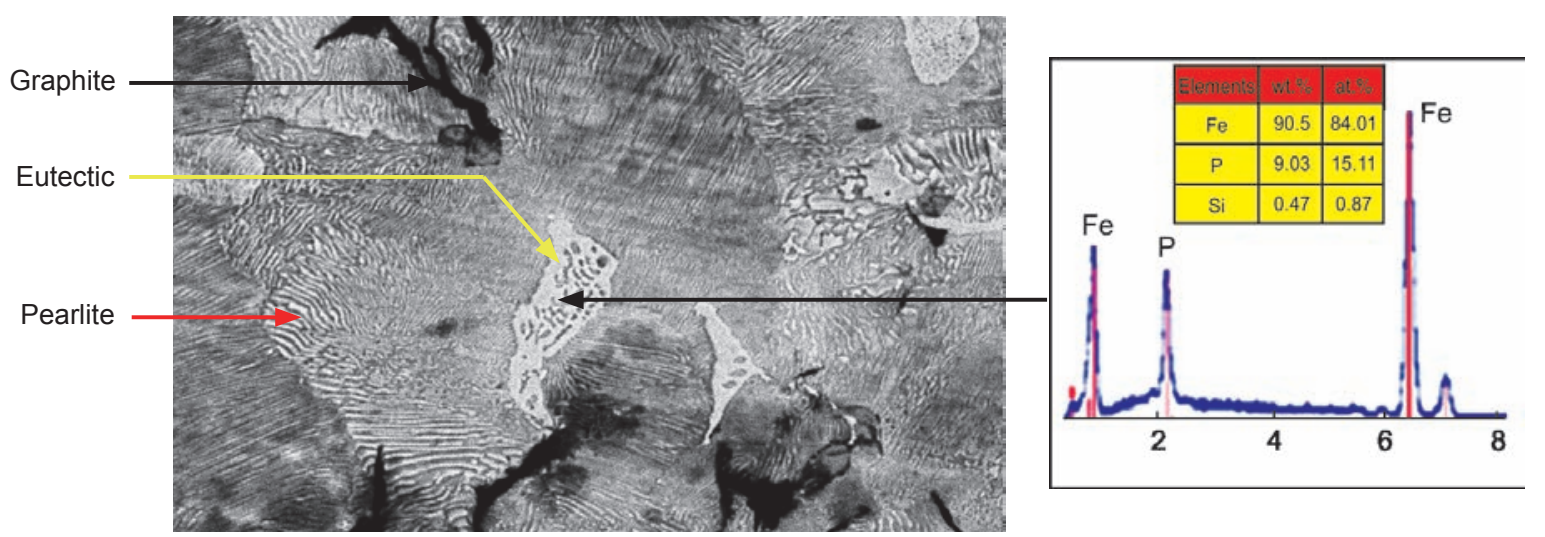

Fig. 2: (a) SEM micrograph of gray cast iron, (b) EDS point analysis of phosphorus eutectic phase, $\mathrm{Fe}_{3} \mathrm{P}$

form of $\mathrm{Fe}_{3} \mathrm{P}$ aggregate due to the low solubility of phosphorus in austenite ${ }^{[18]}$. The XRD spectrum of the control sample (Fig. 3) confirms the presence of these phases in cast iron. The spectrum reveals the presence of a significant amount of ferritic phase, and other peaks are graphite and $\mathrm{Fe}_{3} \mathrm{C}$ cementite phases.

Microhardness measurements from the surface to the center of the sample (Fig. 4) reveal a slight increase in the surface hardness (260 HV) compared to the core hardness (196 HV). This increase in surface hardness can be attributed to the variation in the cooling rates between the core and surface of the sample ${ }^{[11,14]}$.

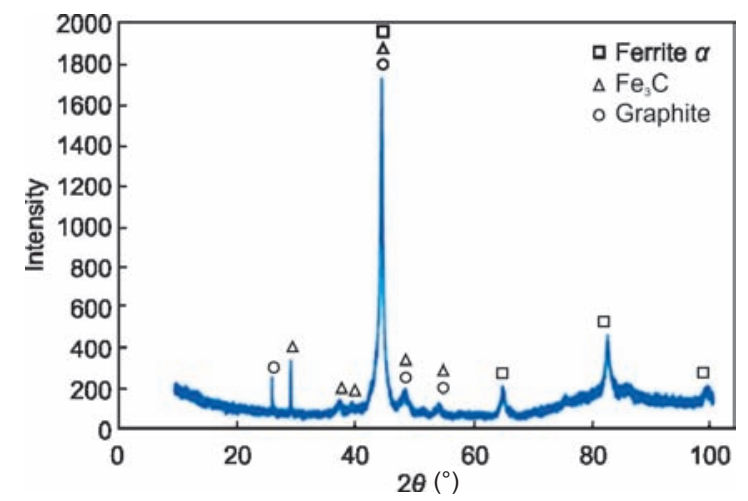

Fig. 3: X-ray diffraction spectrum of untreated cast iron

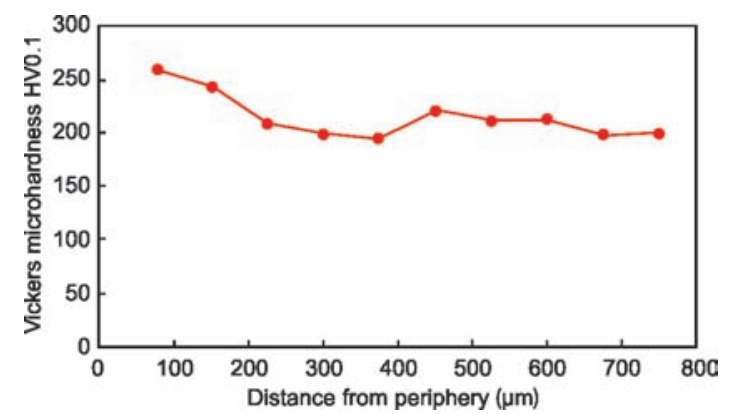

Fig. 4: Vickers microhardness profiles of gray cast iron

\subsection{Characterization of treated cast iron}

\subsubsection{Microstructure of formed layer}

Metallographic observations of E08 (Fig. 5) and E25 (Fig. 6) revealed that the thickness of the two casting parts ( 8 and 25 $\mathrm{mm}$ ) does not have any effect on the microstructure of the layers formed on the gray cast iron. Therefore, only the examination results for sample E25 were used for analysis.

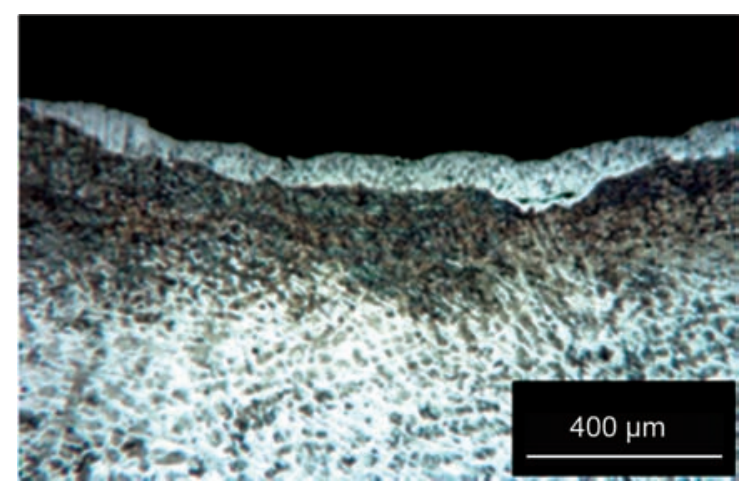

Fig. 5: Optical image of longitudinal cross-section of treated cast iron E08

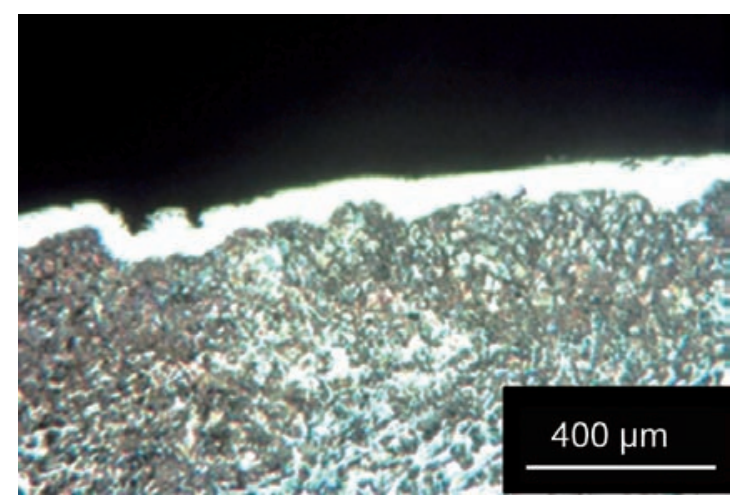

Fig. 6: Optical image of longitudinal cross-section of treated cast iron E25 
The optical microscopy observation on the longitudinal cross-section of the sample (Fig. 6) reveals the formation of a continuous white layer on the treated cast iron (dark contrast).

Scanning electron microscopy (SEM) observation on the longitudinal cross-section of the sample (Fig. 7) reveals the presence of two phases with light and dark gray contrasts. EDS analysis of these phases (Fig. 7) shows that they are binary phases of standard composition: $\mathrm{Al}_{x} \mathrm{Fe}_{y}$ (Table 4).

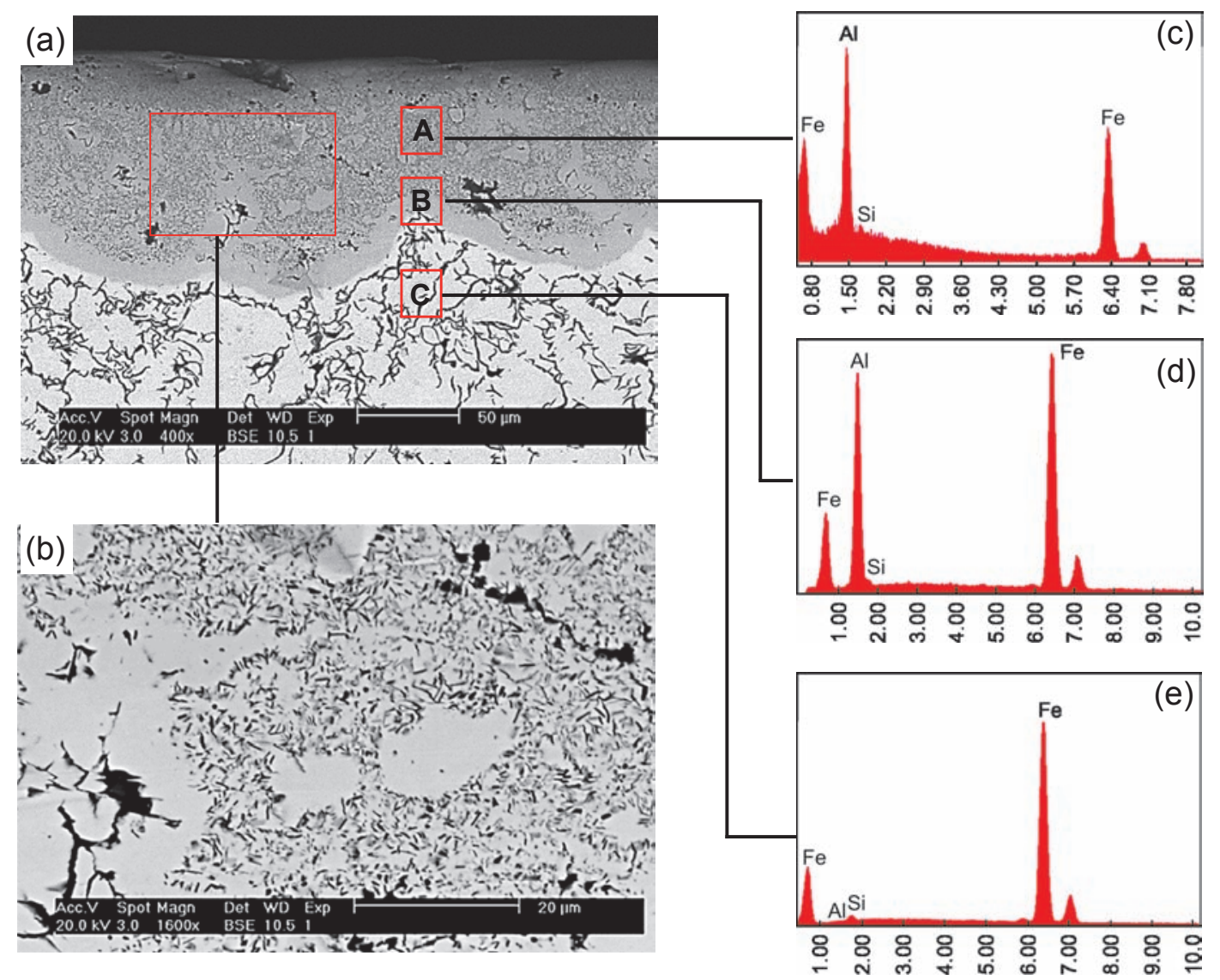

Fig. 7: SEM images of E25 treated cast iron (a) and (b); and EDS spot analyses of zones A, B and C, respectively (c), (d) and (e)

Table 4: Chemical composition and stoichiometry of phases at surface of treated cast iron E25

$\begin{array}{ccccc}\text { Areas } & \text { Elements } & \text { at. \% } & \text { wt.\% } & \text { Proposed phases } \\ \text { A } & \mathrm{Fe} & 35.37 & 53.16 & \\ & \mathrm{Al} & 64.63 & 46.84 & \text { FeAl+FeAl }{ }_{2} \\ \mathrm{~B} & \mathrm{Fe} & 54.11 & 70.98 & \\ & \mathrm{Al} & 45.89 & 29.02 & \mathrm{FeAl} \\ & \mathrm{Fe} & 97.97 & 97.97 & \\ \mathrm{C} & \mathrm{Al} & 0.30 & 0.30 & \text { Basically cast iron } \\ & \mathrm{Si} & 01.73 & 01.73 & \end{array}$

Based on the Fe-Al binary phase diagram ${ }^{[19-20]}$, the twophases inside A zones correspond to the proeutectoid $\mathrm{FeAl}+$ $\mathrm{FeAl} / \mathrm{FeAl}_{2}$. As a result, the microstructure is composed of $\mathrm{FeAl}_{2}$ particles inside FeAl matrix.

The X-ray diffraction spectrum for grazing incidence (Fig. 8) shows four peaks which are perfectly indexed in the FeAl phase crystalline structure. The proportion of $\mathrm{FeAl}_{2}$ phase observed in Fig. 7 is probably below the XRD detection threshold.

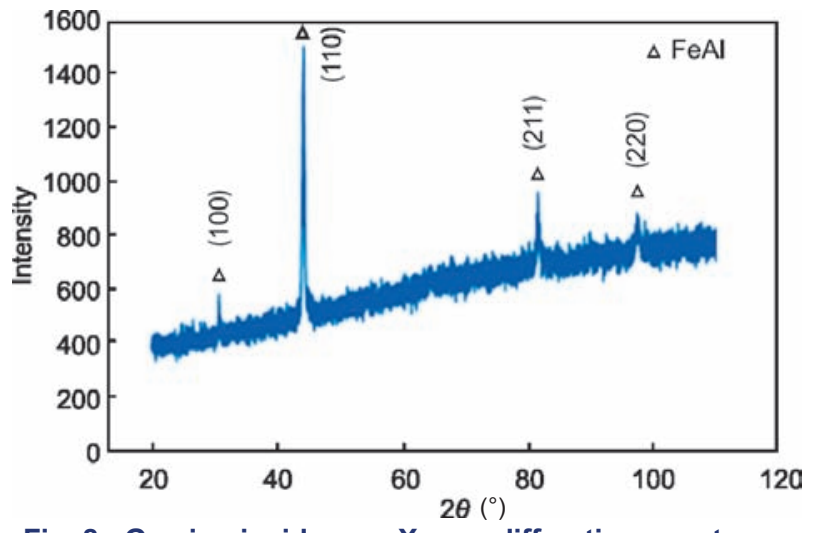

Fig. 8: Grazing incidences $X$-rays diffraction spectrum of treated cast iron E25

\subsubsection{Vickers microhardness variation}

Figure 9 shows the microhardness measurement results from the surface to the core of the part with a pitch of $15 \mu \mathrm{m}$ in zones A and $\mathrm{C}$ and $5 \mu \mathrm{m}$ in zone $\mathrm{B}$.

It can be observed that the surface hardness of the treated cast iron is greater than the core hardness. Figure 9 shows that the average value of the microhardness in Zone A is $450 \mathrm{HV}$, and it is around $300 \mathrm{HV}$ in Zone $\mathrm{B}$. 


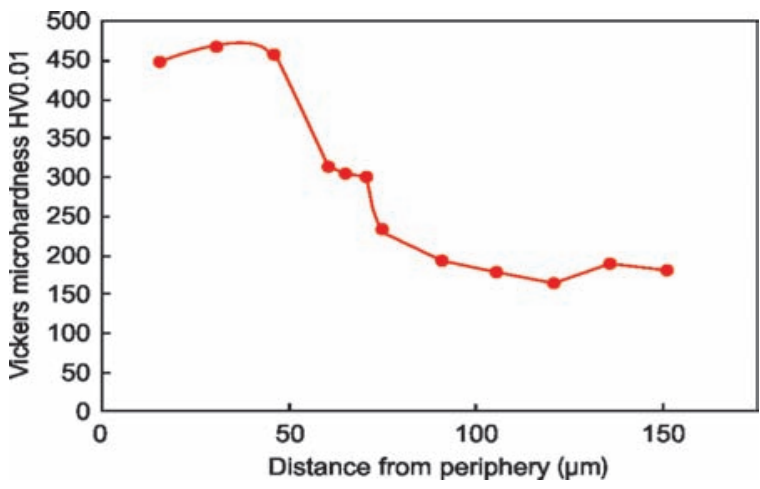

Fig. 9: Vickers microhardness evolution of treated cast iron from surface to core of sample
Vickers microhardness measurements reported by literature ${ }^{[21]}$ in the $\mathrm{Fe}-\mathrm{Al}$ binary alloys recorded maximums in $\mathrm{FeAl}_{2}$ phase. Our measurements are consistent with the literatrue: the FeAl phase (Zone B) has lower microhardness value than those measured in the pro-eutectic Zone $\mathrm{A}\left(\mathrm{FeAl}+\mathrm{FeAl} / \mathrm{FeAl}_{2}\right)$.

\subsection{Mass loss study}

\subsubsection{Effect of exposure time}

Table 5 shows that the mass loss increases with the exposure time in both cases (treated and untreated samples). In addition, the results show that the treated sample (E25) loses less material than the untreated sample during the same exposure time.

Table 5: Results of weight study

\begin{tabular}{|c|c|c|c|c|c|}
\hline Sample & Immersion time (day) & Initial mass (g) & Final mass (g) & Mass loss (g) & Mass loss per area $\left(\mathrm{g} \cdot \mathrm{cm}^{-2}\right)$ \\
\hline \multirow{4}{*}{ Control sample } & 1 & 133.47 & 133.15 & 0.32 & 0.06 \\
\hline & 2 & 120.42 & 119.88 & 0.54 & 0.11 \\
\hline & 3 & 100.67 & 99.92 & 0.75 & 0.14 \\
\hline & 4 & 85.11 & 84.10 & 1.01 & 0.16 \\
\hline \multirow{4}{*}{ E25 } & 1 & 90.29 & 90.15 & 0.14 & 0.03 \\
\hline & 2 & 85.11 & 84.80 & 0.31 & 0.06 \\
\hline & 3 & 80.31 & 79.75 & 0.56 & 0.11 \\
\hline & 4 & 77.07 & 76.32 & 0.75 & 0.15 \\
\hline
\end{tabular}

The corrosion resistance of the treated cast iron can be attributed to the presence of the Al-rich surface layer consisting of $\mathrm{FeAl}$ and $\mathrm{FeAl}_{2}$ phases. In fact, $\mathrm{Fe}-\mathrm{Al}$ alloys are known for their good corrosion and oxidation resistance at low and high temperatures ${ }^{[22-24]}$.

Varin et al. ${ }^{[25]}$ reported that the oxidation and sulfurization resistance of $\mathrm{Fe}-\mathrm{Al}$ alloys increased with the increase in aluminum concentrations ${ }^{[25]}$.

The difference between the two mass losses of the control sample and the treated sample tends to decrease with increasing exposure time due to the progressive consumption of the Al-rich layer present at the surface (Fig. 10).

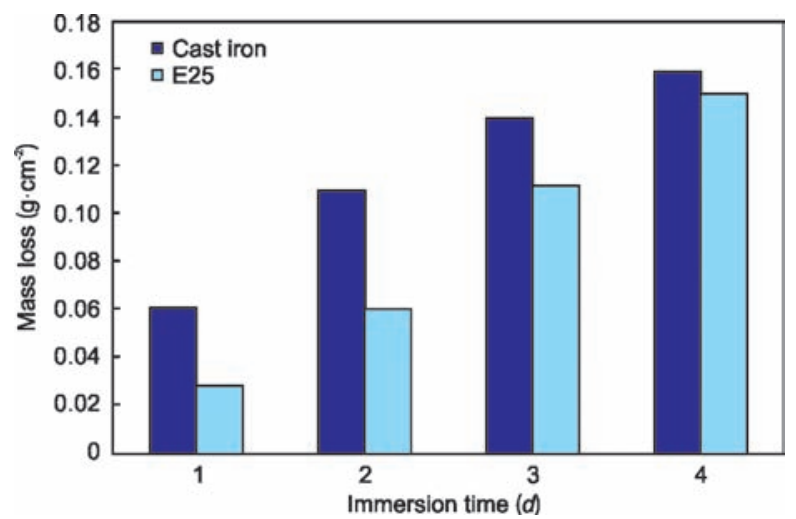

Fig. 10: Mass loss histogram per unit area of control sample and treated E25 as a function of immersion time in a solution of $\mathrm{HCl}(1 \mathrm{M})$

\subsubsection{Corrosion rate}

Table 6 shows the corrosion rates of treated and untreated samples as a function of exposure time.

Table 6 shows high value of the corrosion rate at the beginning of the experiment for the control sample, and it is almost constant over one day. This behavior can be related to the rough surface condition of the material. In general, a highly polished and reflective smooth surface has a greater corrosion resistance. Rough surfaces are capable of capturing dust, salts and humidity, which tend to initiate the localized corrosive attack ${ }^{[26-29]}$.

The variation of the corrosion rate as a function of the exposure time (Table 6) can be divided into two phases for the treated material:

(1) Variable phase (up to 2 days) characterizing the behavior of the Al-rich layer present on the surface. These results show

Table 6: Corrosion rate of control sample and treated sample E25 as a function of immersion time in a solution of $\mathrm{HCl}$ (1 M)

\begin{tabular}{ccc} 
Time (day) & $\begin{array}{c}\text { Control sample } \\
\left(\mathrm{mm} \cdot \text { year }^{-1}\right)\end{array}$ & E25 $\left(\mathrm{mm} \cdot \mathrm{year}^{-1}\right)$ \\
\hline 1 & 0.27 & 0.13 \\
2 & 0.23 & 0.14 \\
3 & 0.21 & 0.17 \\
4 & 0.21 & 0.17
\end{tabular}


that for the same exposure times, the corrosion rate of the treated sample (E25) is significantly lower than that of the untreated sample.

(2) Constant and stable phase over 3 days. In this case, it is likely that the Al-rich layer is consumed, and the protection of the base material is impaired.

\section{Conclusions}

Following conclusions can be drawn from the experimental results:

(1) The synthesis process combining the preparation and surface treatment in a single operation allowed the obtaining of the coated gray cast iron with a uniform and continuous layer.

(2) SEM/EDS analyses, X-ray diffraction results, and the Fe$\mathrm{Al}$ phase diagram revealed the presence of two zones in the superficial layer: proeutectoid $\mathrm{FeAl}+\mathrm{Fe} \mathrm{Al} / \mathrm{FeAl}_{2}$ and $\mathrm{FeAl}$ single phase.

(3) Microhardness measurement showed the treated layer leads to an increase in surface hardness. The average value of the microhardness in Zone A (near the surface of the sample) is $450 \mathrm{HV}$ while it is approximately $300 \mathrm{HV}$ in Zone B (core of the sample). These results are in agreement with the microstructural observations correlated with the literature data concerning the hardness of the binary phases $\mathrm{Fe}_{x} \mathrm{Al}_{y}$.

(4) Immersion of the samples in $\mathrm{HCl}(1 \mathrm{M})$ solution for 1 to 4 days revealed mass loss increases with exposure time in both treated and untreated samples. In contrast, for the same exposure time, the treated sample loses less mass than the control sample. This result is related to the presence of $\mathrm{FeAl}$ and $\mathrm{FeAl}_{2}$ phases in the surface of the treated cast. These phases are known for their good corrosion resistance.

(5) The difference of mass loss between the control and the treated sample tends to decrease with increasing exposure time. This result can be explained by the progressive consumption of the superficial layer which becomes dominant with increasing the immersion time.

\section{References}

[1] Gundlach R B, Doane D V. Alloy Cast Irons, ASM Handbook, 2005, 1: 150-180.

[2] Zhou $\mathrm{W}$, Zhu H, Zheng D, et al. Niobium alloying effect in high carbon equivalent grey cast iron. China Foundry, 2011, 8(1): 36-40.

[3] Ik-Min P, Shin K S. Microstructure and wear properties of low-alloy phosphoric gray cast irons. Metals and Materials International, 1995, 1: 63-70.

[4] Vadiraj A, Kamaraj M, Sreenivasan V S. Wear and friction behavior of alloyed gray cast iron with solid lubricants under boundary lubrication. Tribology International, 2011, 44: 1168-1173.
[5] Xu W, Ferry M, Wang Y. Influence of alloying elements on ascast micro- structure and strength of gray iron. Materials Science and Engineering: A, 2005, 390 (1-2): 326-33.

[6] Murry G. Metallurgy Handbook, Vol: Metals, Alloys, Properties, 2010. (In French).

[7] Bouitna M, Boutarek-Zaourar N, Mansour S, et al. Surface hardening of gray cast iron induced by surface treatement in the mold, Materials \& Techniques, 2018, 105(3): 305

[8] Bramfitt B L, Benscoter A O. Metallographer's Guide: Practice and Procedures for Irons and Steels, ASM International, 2002.

[9] Stefanescu D M. Classification and Basic Metallurgy of Cast Iron, ASM Handbook, 2005, 1: 17-33.

[10] Aggen G, et al. ASM Handbook- Gray Iron Properties and Selection. ASM International, 2005, 1: 34-64.

[11] Schneidewind R, McElwee R G. Composition and Properties of Gray Iron, Parts I and II. Trans. AFS, 1950, 58: 312-330.

[12] Guide to Engineered Materials, Property Comparison Tables. Adv. Mater. Process, ASM International, 2001, 159 (12): 46, 2001.

[13] Alp T, Wazzan AA, Imaz Y. Microstructure-properties relationship in cast irons. Abrasion J. Sci. Eng., 2005, 30: 163.

[14] Radzikowska J M. Cast Iron, Metallography and Microstructures. ASM International, 2004, 9: 565-587.

[15] Zum Gahr K H. Microstructure and wear materials. Elsevier, Amsterdam, 1987.

[16] Vander Voor G F. Metallography: Principles and Practice. McGraw-Hill Book, ASM International, 1984

[17] Winte H C. Gray Iron Casting Section Sensitivity. Trans. AFS, 1946, 5: 436-443.

[18] Margerie J C. Properties of ordinary cast iron, Technical engineer, 2003. (In French)

[19] X.Li, A.Scherf: The Al-Rich part of the Fe-Al phase diagram, 2016. DOI: 10.1007/s11669-015-0446-7.

[20] Poupeau P. Equilibrium diagrams of binary alloys. Technical Engineer, 2003. (In French)

[21] Fekrache A. Microstructural study of aluminum -iron alloys, memory of magister. Badji Mokhtar University - Annaba ALGERIA, 2008. (In French)

[22] Grosdidier Th, Ji G, Bernard F, et al. Synthesis of bulk FeAl nanostructured materials by HVOF spray forming and spark plasma sintering. Intermetallics, 2006, 14 (10-11): 1208-1213.

[23] Godlewska E, Szczepanik S, Mania R, et al. FeAl materials from intermetallic powders. Intermetallics, 2003, 1 (1-2): 307-312.

[24] Martinez M, Viguier B, Maugis P. Relation between composition, microstructure and oxidation in iron aluminides. Intermetallics, 2006, 14 (10-11): 1214-1220.

[25] Varin R A, Bystrzycki J, Calka A. Characterization of nanocrystalline $\mathrm{Fe}-45$ at. $\% \mathrm{Al}$ intermetallic powders obtained by controlled ball milling and the influence of annealing. Intermetallics, 1999, 7 (8): 917-930.

[26] Davison R M, Johnson M J. Corrosion of Stainless Steels, ASM Handbook, 2005, 13: 1341.

[27] Crolet J L. Passivable metals and alloys - rules of choice and typical jobs. Technical Engineer, 2003. (In French).

[28] Davis J R, Ed., ASM Handbook - Surface engineering for corrosion and wear resistance. ASM International, 2001.

[29] Shreir L L, Jarman R A, Burstein G T. Corrosion Metal. Environment Reactions, 2000, 1. 